\title{
Two unusual features in a child with Berardinelli-Seip congenital generalised lipodystrophy
}

\author{
M P Senanayake ${ }^{1}$, I Karunaratne ${ }^{2}$ \\ Ceylon Medical Journal 2014; 59: 103-105
}

\section{Introduction}

Berardinelli-Seip congenital generalised lipodystrophy (BSCGL) is an extremely rare autosomal recessive disorder characterised by congenital absence of functional adipocytes causing lipoatrophy, dyslipidemia and fat maldistribution [1]. Fat deposited in liver, heart and muscle result in stetosis-induced cirrhosis, cardiac failure, insulin resistance and diabetes mellitus. We report two additional findings of aortic stenosis, and testicular microlithiasis in a Sri Lankan boy who fulfilled the clinical and metabolic diagnostic criteria of BSCGL.

\section{Case report}

An eleven-years old boy, whose parents were first cousins presented with altered behaviour and drowsiness. At birth he had weighed $1.5 \mathrm{~kg}$. He had abnormal facies, 'empty cheeks' and failure to thrive was noted in early infancy. At two years he had a voracious appetite and looked "bigger and older" than his peers. He had significant learning difficulties in school.

On general examination there was acromegaloid facies (Figure 1), verrucous-like acanthosis nigricans, gynecomastia, muscular limbs and protuberant abdomen (Figure 2). Weight (45 kg) and height $(148 \mathrm{~cm})$ were at 90th and 75th centiles respectively. He was pre-pubertal, with no axillary or pubic hair. Stretched penile length was $3 \mathrm{~cm}$ (expected for age $>4.5 \mathrm{~cm}$ ). Both testes were symmetrically enlarged; testicular volumes $=6 \mathrm{~cm}^{3}$. (expected for age is $<2 \mathrm{~cm}^{3}$ ). Systemic examination found that blood pressure was 140/90 mm Hg (above 95th centile) and there was an ejection systolic murmur in the aortic area without cardiomegaly. Firm liver was palpable $4 \mathrm{~cm}$ below the costal margin, spleen was not palpable. There was free fluid in the abdomen and reduced air entry in both lung bases. Glasgow coma scale (GCS) was 7/15 with no meningeal irritation or focal neurological signs. A clinical diagnosis of BSCGL with hepatic encephalopathy complicating steatosis-induced cirrhosis was made.

Lipid profile showed; serum triglycerides $307 \mathrm{mg} / \mathrm{dl}$ (high range 200-499 mg/dl), total serum cholesterol $98 \mathrm{mg} /$ dl (<200 mg/dl), serum very low density lipoprotein(VLDL)
$61.4 \mathrm{mg} / \mathrm{dl}$ (normal range 10-41 mg/dl), serum high density lipoprotein (HDL) $34 \mathrm{mg} / \mathrm{dl}$ and serum low density cholesterol $3 \mathrm{gm} / \mathrm{dl}$. Fasting blood glucose was $10.6 \mathrm{mmol} /$ l (normal $<5.6 \mathrm{mmol} / \mathrm{l}), 75 \mathrm{~g}$ oral glucose tolerance test found serum glucose $17 \mathrm{mmol} / \mathrm{l}$ at 2 hours (normal $<11.1$ $\mathrm{mmol} / \mathrm{l}$ ). Liver profile- serum alanine aminotransferase 126 $\mathrm{Iu} / \mathrm{l}$, serum aspartate aminotransferase $207 \mathrm{u} / \mathrm{l}$, serum albumin 22 g/l (34-50 g/l), serum globulin 39 g/l, prothrombin time $21.4 \mathrm{~s}$ (control $12 \mathrm{~s}$ ), PT/INR 1.79. Renal functions - serum creatinine $39 \mathrm{mmol} / \mathrm{l}$ (27-88), serum sodium $138 \mathrm{mmol} / \mathrm{l}$ (135-145) and potassium $3.7 \mathrm{mmol} / \mathrm{l}$ (3.5-5.3). Haemoglobin $13.4 \mathrm{~g} / \mathrm{dl}$, total white cell count 8.3 $\times 10^{9} / \mathrm{l}(\mathrm{N}-70 \%, \mathrm{~L}-25 \% \mathrm{E}-1 \%, \mathrm{M}-4 \%)$ and platelet count was $161,000 / \mathrm{mm}^{3}$.

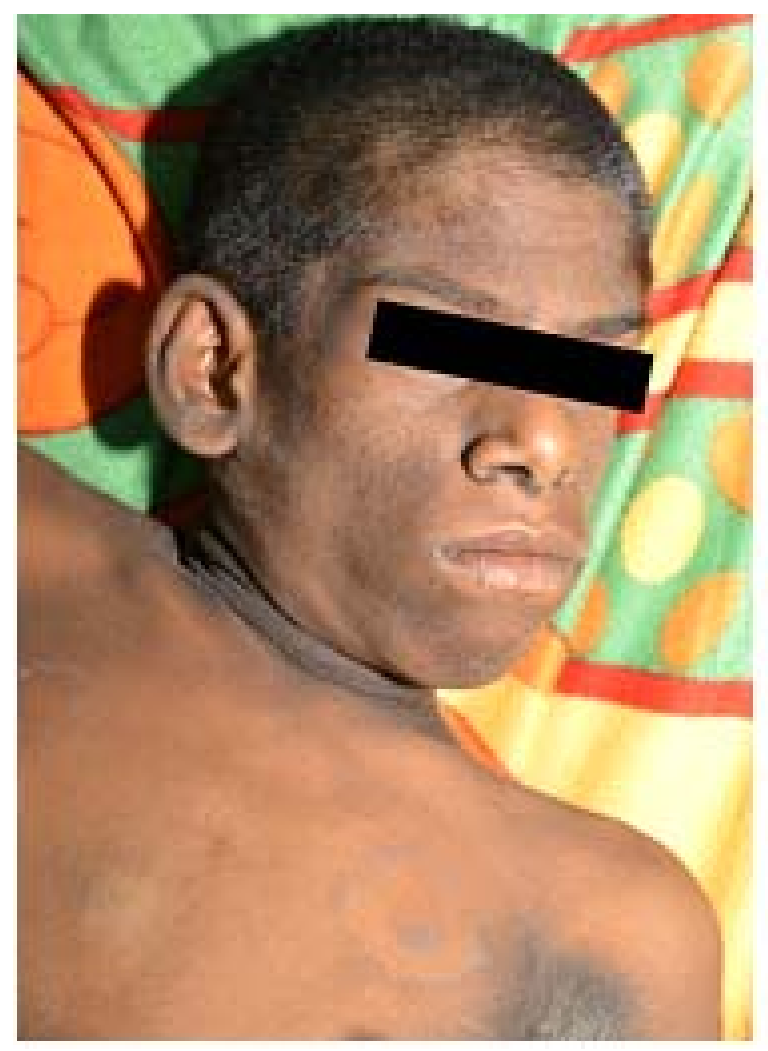

Figure 1. Acromegaloid facies (prominent orbital ridges, prognathism) and lipoatrophy of face.

Department of ${ }^{1}$ Paediatrics, Faculty of Medicine, Univestiy of Colombo and ${ }^{2}$ Paediatrics Unit, Lady Ridgeway Hospital for Children, Colombo, Sri Lanka.

Correspondence: MPS, e-mail: <manouri.senanayake@gmail.com>. Received 21 February 2014 and revised version accepted 5 June 2014. Competing interests: none declared. 


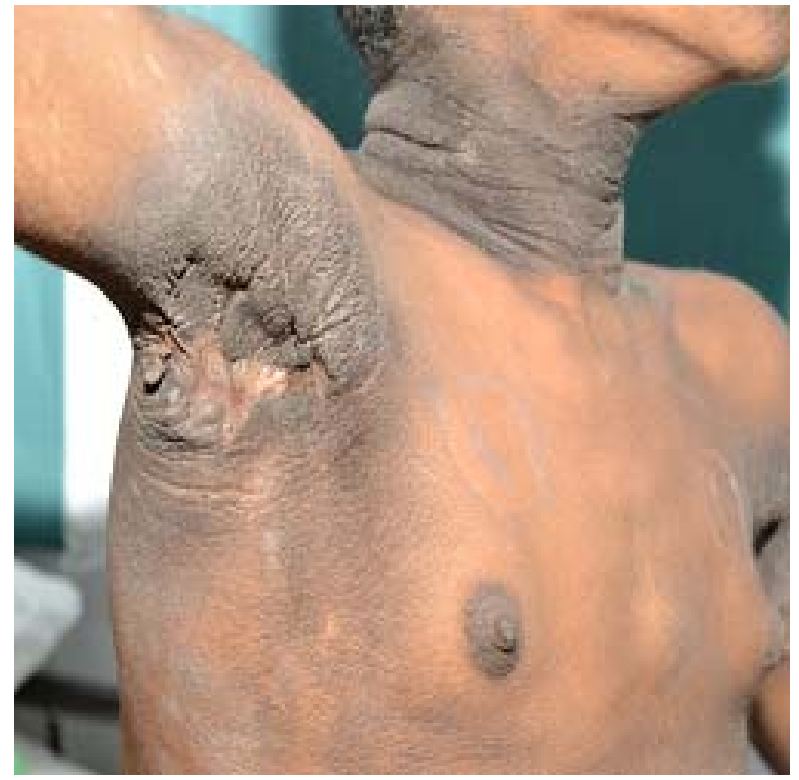

Figure 2. Severe verrucous-like acanthosis nigricans in neck and axilla.

Echocardiography showed mild aortic valvular stenosis, normal bi-ventricular function and no cardiac muscle hypertrophy. Electrocardiograph was normal. Computerised tomography of brain was normal. Abdominal ultrasonography found ascites, hepatomegaly with increased echogenicity and diffuse fatty infiltration and tiny bright echoes diffusely scattered throughout both testes (Figure 3). Testicular biopsy found immature spermatogenic cells and calcified bodies within semeniferous tubules in several cross-sections (Figure 4). There was no stromal fat deposition.

Hepatic encephalopathy resolved with symptomatic treatment. Despite regular medical follow-up for hepatic and cardiac status, dietary modification (high-fibre, high-calorie low-fat, regular sized meals low in easily digestible carbohydrates) and a physical exercise regime he succumbed to acute liver failure seven months later $[2,3]$.

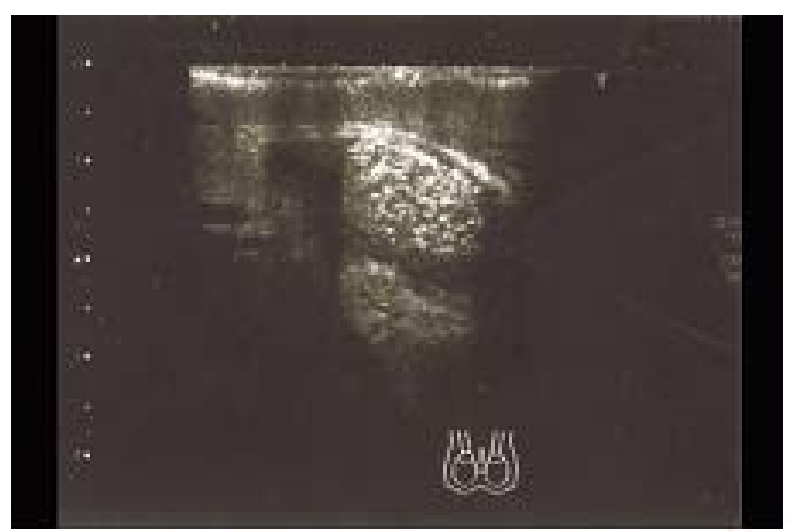

Figure 3. Ultrasonographic image of testes showing multiple hyper-echoic foci.

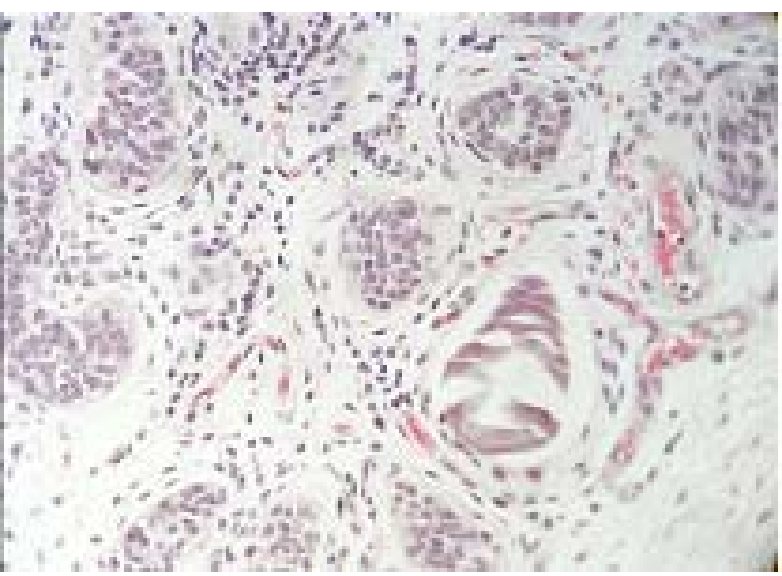

Figure 4. Histology micrograph (magnification $\times 40$ ) showing a calicified body (marked with arrow ) and several seminiferous tubules containing immature spermatogonia interspersed with Sertoli cells.

\section{Discussion}

In this child, clinical and metabolic manifestations fulfilled all five major criteria (generalised lipoatrophy, acromegaloid features, steatosis-induced cirrhosis, hepatomegaly, hypertriglyceridemia, and insulin resistance) of BSCGL; although three major or two major plus two minor criteria (cardiomyopathy, hirsuitsm, phlebomegaly, precocious puberty in females, bone cysts and intellectual impairment) would have been adequate [4]. Lack of resources prevented genetic analysis.

Testicular atrophy is a common finding in liver failure but this child had macroorchidism. Enlarged testes have been reported rarely in BSCGL, but to the best of our knowledge there is no explanatory cause documented. Our finding of numerous microcalcosperites on testicular biopsy has not been reported previously. It is compatible with the ultrasonic findings of no fat deposits in the testis. In BSCGL, apart from liver, heart and muscle, excessive fat deposition in orbit, tongue, palms, soles, breast and vulva have been documented [5,6].

The other unusual finding in this child was aortic stenosis. Previously reported cardiovascular abnormalities in BSCGL are arterial hypertension, hypertrophic cardiomyopathy, ventricular diastolic dysfunction, arrhythmias, pulmonary hypertension and pulmonary artery branch stenosis [7].

\section{Acknowledgements}

We thank staff of the Departments of Radiology, Cardiology and Pathology of Lady Ridgeway Children's Hospital Colombo and Prof. Preethika Angunawela of the Department of Pathology, Faculty of Medicine, for her assistance and providing us with photomicrography. 


\section{References}

1. Garg A. Acquired and Inherited Lipodystrophies. New England Journal of Medicine 2004; 350: 1220-34.

2. Ferraria N, Pedrosa C, Amaral D, Lopes L. Berardinelli-Seip syndrome: highlight of treatment challenge. British Medical Journal Case Reports 2013; doi:10.1136/bcr-2012-007734.

3. Moran SA, Patten N, Young JR, Cochran E, Sebring N, Reynolds J, et al. Changes in body composition in patients with severe lipodystrophy after leptin replacement therapy. Metabolism 2004; 53: 513-9.

4. Indumathi C K, Lewin S, Ayyar V. Berardinelli Seip syndrome with insulin-resistant diabetes mellitus and stroke in an infant. Indian Journal of Endocrine and Metabolism 2011; 15: 62-4.

5. Garg A, Fleckenstein JL, Peshock RM, Grundy SM. Peculiar distribution of adipose tissue in patients with congenital generalized lipodystrophy. Journal of Clinical Endocrinology and Metabolism 1992; 75: 358-61.

6. Mandal K, Aneja S, Seth A, Anamita K. Khandpur S,Kumar A, Khadgawat R. Berardinelli-Seip congenital lipodystrophy. Indian Paediatrics 2006; 43: 440-5

7. Uzun O, Blackburn ME C, Gibbs JL. Congenital total lipodystrophy and peripheral pulmonary artery stenosis. Archives of Diseases in Childhood 1997; 76: 456-7. 